\title{
Gender differences of health behaviors and quality of life of Koreans with asthma
}

\author{
Yeonsoo Jang ${ }^{1}$, Hyera Yoo $^{2 *}$ \\ ${ }^{1}$ College of Nursing, Nursing Policy and Research Institute, Yonsei University, South Korea \\ ${ }^{2}$ College of Nursing, Ajou Univeristy, South Korea \\ Email: $\underline{\text { hryoo@ajou.ac.kr }}$
}

Received 21 July 2013; revised 22 August 2013; accepted 19 September 2013

Copyright (C) 2013 Yeonsoo Jang, Hyera Yoo. This is an open access article distributed under the Creative Commons Attribution License, which permits unrestricted use, distribution, and reproduction in any medium, provided the original work is properly cited.

\begin{abstract}
Purpose: The purpose of this study was to explore gender differences in health-behaviors and quality of life (QOL) in Koreans with asthma. Methods: Participants, selected from the 2009 Korean National Health and Nutritional Examination Survey VI, included 305 individuals $($ men $=128$, women $=177)$ with asthma and over 19 years old. Health behaviors were measured by questions about disease management, health choices, and functional and psychological status. QOL was measured with the European Quality of Life-5D (EQ-5D). Results: In health behaviors, $51.3 \%$ of women and $37.7 \%$ of men suffered from wheezing at rest. About $41 \%$ of men and $10 \%$ of women were smokers. One half of the participants were not taking medication and this was not significantly different by gender. The number of women with symptoms of depression was significantly higher than men. The EQ-5D index score of women was significantly lower than that of men. Conclusion: Women with asthma were more likely to have psychological problems and discomfort than men. Understanding gender differences in asthma is important to the development of effective, tailored asthma management strategies to cope with symptoms and improve health behaviors and QOL for people with asthma.
\end{abstract}

Keywords: Asthma; Health Behavior; Quality of Life; Gender; Korean

\section{INTRODUCTION}

Asthma is a chronic disease characterized by recurrent attacks of breathlessness and wheezing, which vary in severity and frequency. The World Health Organization reported that 235 million people suffer from asthma

\footnotetext{
"Corresponding author.
}

across the world [1]. In 2007, 34 million people were diagnosed with asthma in the United States, and asthma accounted for 3447 deaths. After the age of 20, asthma death rates are higher among women than men in the United States [2]. In Korea, the prevalence of asthma was $7.7 \%$ among adults aged 19 years and older in 2009; in comparison, the prevalence of type II diabetes mellitus and cancer were $9.6 \%$ and $2.9 \%$, respectively, in the same year [3].

Asthma impairs the quality of life (QOL) and physical and psychological health status such as depression, distress, or limited activities [4]. Patients with asthma have reduced exercise capacity and may be limited in work performance [5]. Koreans with asthma are likely to have similar health outcomes as patients in other countries. Previous studies report that Koreans with chronic obstructive lung disease engaged in poor health behaviors. Moreover, the QOL of Koreans with asthma is lower than that of Koreans with chronic obstructive lung disease $[6,7]$.

The results of previous studies suggest that tailored interventions, based on gender, may be needed because there are gender-related differences among people with asthma. It is known that the prevalence of asthma and the rates of mortality and hospitalization in women are higher than those in men $[8,9]$. In addition, it has been reported that the QOL and health status of women with asthma are lower than those of men $[10,11]$. However, gender differences in health behaviors and QOL among Koreans with asthma are poorly understood.

The purpose of this study was to examine gender differences in disease management, health behaviors, and QOL using data from the 2009 Korean National Health and Nutritional Examination Survey (KNHANES IV).

\section{METHODS}

\subsection{Participants}

The KNHANES IV was a nation-wide study using a 
complex sample design for the selection of representative household units $(N=24,871)$ of non-institutionalized civilians in South Korea conducted by the Korean Center for Disease Control and Prevention in 2009. KNHANES IV consisted of three components: the Health Interview Survey, the Health Examination Survey, and the Nutrition Survey [12]. From the KNHANES IV database, 305 individuals $($ men $=128$, women $=177)$ aged 19 years or over and diagnosed with asthma by a physician were selected for the present study.

\subsection{Measurements}

Demographic characteristics. Age, marital status, education level, occupation, household income, and comorbidity were collected to identify the demographic characteristics of the sample.

Health behaviors. Health behaviors were measured by questions about disease management, health choices, and functional and psychological status. The disease management category included questions about current treatment status, medication compliance, the status of symptoms (wheezing), and asthma attacks. The health choices category assessed the use of tobacco or alcohol, and the frequency of exercise, health examinations, and influenza vaccinations.

Functional health was assessed by activity limitations, measured using a dichotomous scale (yes/no), and perceived health status, which was represented by the choice of good, fair, or poor. Psychological health was assessed by symptoms of depression in the last two weeks, measured with a dichotomous scale (yes/no), and the level of stress, which was measured with a 4-point Likert scale (1 $=$ very much to $4=$ very little).
Quality of life. The European Quality of Life-5D (EQ5D) scale was used to assess the quality of life. The EQ$5 \mathrm{D}$ consists of questions about five items - mobility, self-care, normal activities, pain, and anxiety/depression - on a dichotomous scale (no problems/problems). In addition, the EQ-5D assesses overall QOL using a visual analysis scale of 0 to 100 .

The EQ-5D index scores are calculated based on responses to the five-item questionnaire, preference weights, and an algorithm. The weights and algorithm were determined by a study with a UK population that used data from the Measurement and Valuation of Health survey [13]. The index score was used to evaluate the overall QOL.

\subsection{Ethical Considerations}

This study is a retrospective study that used and analyzed the data from the 2009 KNHANES survey; therefore, approval from IRB was not required.

\subsection{Data Analysis}

Using PASW Statistics 18, a general linear model and cross-tabulation analysis were used to explore demographic characteristics and gender differences in health behaviors and QOL. All values were weighted.

\section{RESULTS}

\subsection{Demographic Characteristics}

The demographic characteristics of participants are presented in Table 1. The mean age of men was 48.1 years (SE $=1.97$, ranging: $19-89$ ) and the mean age of

Table 1. Demographic characteristics by gender $(\mathrm{N}=305)$.

\begin{tabular}{|c|c|c|c|c|}
\hline Variables & $\begin{array}{c}\text { Total } \\
\mathrm{N}=305\left(\%^{\dagger}\right)\end{array}$ & $\begin{array}{c}\text { Men } \\
\mathrm{n}=128\left(\%^{\dagger}\right)\end{array}$ & $\begin{array}{c}\text { Women } \\
\mathbf{n}=177\left(\%{ }^{\dagger}\right)\end{array}$ & $t$ or $x^{2}$ ( $p$ value) \\
\hline Age, years, mean $^{\dagger}\left(\mathrm{SE}^{\dagger}\right)$ & $55.9(17.43)$ & $48.1(1.97)$ & $52.2(1.57)$ & $-1.595(0.113)$ \\
\hline Marital status & & & & $32.98(0.000)$ \\
\hline Married/living with spouse & $201(61.3)$ & $102(92.3)$ & 99 (61.9) & \\
\hline Single/Divorced/Widowed & $104(34.7)$ & $8(7.7)$ & $62(38.1)$ & \\
\hline Education & & & & $26.57(0.000)$ \\
\hline Elementary or less & $136(34.5)$ & $42(21.1)$ & $94(46.1)$ & \\
\hline Middle school & $36(11.0)$ & $14(11.1)$ & $22(11.0)$ & \\
\hline High school & $77(32.3)$ & $45(44.9)$ & $32(21.6)$ & \\
\hline College or over & $56(21.1)$ & $27(22.9)$ & $29(21.4)$ & \\
\hline Occupation & & & & $33.90(0.000)$ \\
\hline Yes & $156(53.9)$ & $85(71.9)$ & $71(38.5)$ & \\
\hline No & $149(46.1)$ & $43(28.1)$ & $106(61.5)$ & \\
\hline \multicolumn{5}{|l|}{ Comorbidity ${ }^{\dagger \dagger}$} \\
\hline Hypertension & $103(33.8)$ & $40(26.4)$ & $63(32.7)$ & $1.46(0.292)$ \\
\hline Arthritis & $106(34.8)$ & $27(20.3)$ & $79(35.5)$ & $8.75(0.012)$ \\
\hline Diabetes Mellitus & $39(10.6)$ & $15(10.6)$ & $24(10.6)$ & $0.00(0.991)$ \\
\hline
\end{tabular}

${ }^{\dagger}$ weighted values. ${ }^{\dagger \dagger}$ Multiple response. 
women was 52.2 years ( $\mathrm{SE}=1.57$, range: 41 - 88 year). There was no significant difference for mean age between men and women. The number of women who were diagnosed with arthritis was significantly higher than that of men $(p=0.012)$.

\subsection{Health Behaviors}

The mean age at diagnosis of asthma of men $(31.3 \pm 2.66)$ was significantly younger than that of women $(40.8 \pm$
1.71) $(p=0.005)$. Women were more likely than men to have wheezing at rest $(p=0.027)$. One half of both men and women had never taken medication for asthma, and there was no gender difference on this variable (Table 2).

One half of the men $(41.1 \%)$ smoked and number of cigarettes was 15.3 per day. Twenty-six percent of women reported drinking. About $51 \%$ of the men and $64 \%$ of the women did not exercise (Table 3 ).

The number of women with symptoms of depression

Table 2. Comparison of disease management by gender $(\mathrm{N}=305)$.

\begin{tabular}{|c|c|c|c|c|}
\hline \multirow{2}{*}{ Variables } & \multirow{2}{*}{$\begin{array}{c}\text { Total } \\
\mathrm{N}=305\left(\%^{\dagger}\right)\end{array}$} & \multirow{2}{*}{$\begin{array}{c}\text { Men } \\
n=128\left(\%^{\dagger}\right)\end{array}$} & \multirow{2}{*}{$\begin{array}{c}\text { Women } \\
\mathbf{n}=177\left(\%^{\dagger}\right)\end{array}$} & \multirow{2}{*}{$t$ or $x^{2}$ ( $p$ value $)$} \\
\hline & & & & \\
\hline Age at diagnosis, years, $\operatorname{mean}^{\dagger}\left(\mathrm{SE}^{\dagger}\right)$ & $36.66(1.53)$ & $31.3(2.66)$ & $40.8(1.71)$ & $-2.89(0.005)$ \\
\hline Current treatment & & & & $1.98(0.222)$ \\
\hline Yes & $76(22.3)$ & $33(18.6)$ & $43(25.4)$ & \\
\hline No & $229(77.7)$ & $95(81.4)$ & $137(74.6)$ & \\
\hline Rest & $152(45.0)$ & $56(37.7)$ & $96(51.3)$ & $5.70(0.027)$ \\
\hline Exercise & $107(31.8)$ & $43(28.9)$ & $64(34.4)$ & $2.21(0.329)$ \\
\hline Taking Medication & & & & $3.52(0.478)$ \\
\hline Always, regular & $49(14.6)$ & $25(12.2)$ & $24(16.5)$ & \\
\hline Often, or as needed & $83(26.1)$ & $27(22.9)$ & $56(28.9)$ & \\
\hline Never & $154(52.2)$ & $68(57.7)$ & $86(47.5)$ & \\
\hline Asthma attack in the previous year & & & & $0.32(0.882)$ \\
\hline Yes & $35(10.3)$ & $16(9.3)$ & $19(11.2)$ & \\
\hline No & $251(82.5)$ & $104(83.5)$ & $147(81.6)$ & \\
\hline Unknown & $19(7.2)$ & $8(7.2)$ & $11(7.1)$ & \\
\hline
\end{tabular}

${ }^{\dagger}$ weighted values.

Table 3. Comparison of health choices by gender $(\mathrm{N}=305)$.

\begin{tabular}{|c|c|c|c|c|}
\hline \multirow{2}{*}{ Variables } & Total & Men & Women & \multirow{2}{*}{$t$ or $x^{2}$ ( $p$ value $)$} \\
\hline & $\mathbf{N}=305\left(\%^{\dagger}\right)$ & $\mathrm{n}=128\left(\%^{\dagger}\right)$ & $\mathbf{n}=177\left(\%^{\dagger}\right)$ & \\
\hline Smoking & & & & $99.0(0.000)$ \\
\hline Current & 67 (24.6) & $50(41.1)$ & $17(10.5)$ & \\
\hline Quit & $65(21.3)$ & $50(35.5)$ & $15(9.1)$ & \\
\hline No & $173(54.1)$ & $28(23.5)$ & $145(80.4)$ & \\
\hline Smoking, cigarettes/day, mean ${ }^{\dagger}\left(\mathrm{SE}^{\dagger}\right)$ & $13.44(0.754)$ & $15.3(0.983)$ & $7.12(0.754)$ & $9.43(0.000)$ \\
\hline Drinking & & & & $16.35(0.000)$ \\
\hline Yes & $63(17.9)$ & $12(8.3)$ & $51(26.1)$ & \\
\hline No & $242(82.1)$ & $116(91.7)$ & $126(73.9)$ & \\
\hline Regular exercise (moderate) & & & & $5.01(0.174)$ \\
\hline Not at all & $186(58.0)$ & $73(51.2)$ & $113(63.8)$ & \\
\hline Less than 3 days & $66(23.8)$ & $27(27.2)$ & $39(20.8)$ & \\
\hline Health Examination in last years & & & & $0.37(0.597)$ \\
\hline Yes & $165(48.9)$ & $72(47.0)$ & $93(50.5)$ & \\
\hline No & $140(51.1)$ & $56(53.0)$ & $84(49.5)$ & \\
\hline Influenza Vaccination & & & & $1.11(0.444)$ \\
\hline Yes & $161(46.9)$ & $64(43.7)$ & $97(49.7)$ & \\
\hline No & $144(53.1)$ & $64(56.3)$ & $80(50.3)$ & \\
\hline
\end{tabular}

${ }^{\dagger}$ weighted values. 
in the last two weeks was significantly higher than the number of men $(p=0.022)$. Approximately $26 \%$ of men and $33 \%$ of women reported some limits on activity, but there were no gender differences. Similarly, current health status was not significantly different between men and women (Table 4).

\subsection{Quality of Life}

The overall QOL of all subjects was moderate and there was no gender difference. However, there were significant differences on subscales of EQ-5D: women reported more problems related to mobility $(p=0.001)$, usual activity $(p=0.036)$, and pain/discomfort $(p=0.001)$ than men. The EQ-5D index score of women was significantly lower than that of men $(p=0.003)$ (Table 5).

\section{DISCUSSION}

This study was conducted to explore gender differences

Table 4. Comparison of functional and psychological health status by gender $(\mathrm{N}=305)$.

\begin{tabular}{|c|c|c|c|c|}
\hline \multirow{2}{*}{ Variables } & Total & Men & Women & \multirow{2}{*}{ tor $x^{2}$ ( $p$ value) } \\
\hline & $\mathrm{N}=305\left(\%^{\dagger}\right)$ & $\mathrm{n}=128\left(\%^{\dagger}\right)$ & $n=177\left(\%^{\dagger}\right)$ & \\
\hline Stress & & & & $0.90(0.881)$ \\
\hline Very much & $25(9.6)$ & $12(10.6)$ & $13(8.7)$ & \\
\hline Much & $91(32.4)$ & $38(32.9)$ & $53(31.9)$ & \\
\hline Little & $143(46.1)$ & $56(43.5)$ & $87(48.3)$ & \\
\hline Very little & $46(12.0)$ & $22(13.0)$ & $24(11.1)$ & \\
\hline Depression in last two weeks & & & & $6.51(0.022)$ \\
\hline Yes & $68(21.2)$ & $21(14.7)$ & $47(26.7)$ & \\
\hline No & $237(78.8)$ & $107(85.3)$ & $130(73.3)$ & \\
\hline Activity limitation & & & & $1.45(0.225)$ \\
\hline Yes & $108(29.6)$ & $42(26.2)$ & $66(32.6)$ & \\
\hline No & $197(70.4)$ & $86(73.8)$ & $111(67.4)$ & \\
\hline Current Health Status & & & & $0.67(0.788)$ \\
\hline Good & $78(27.4)$ & $38(29.7)$ & $40(25.5)$ & \\
\hline Moderate & $80(26.8)$ & $34(28.1)$ & $46(29.0)$ & \\
\hline Poor & $147(44.0)$ & $56(42.3)$ & $91(45.4)$ & \\
\hline
\end{tabular}

${ }^{\dagger}$ weighted values.

Table 5. Comparison of quality of life by gender $(\mathrm{N}=305)$.

\begin{tabular}{|c|c|c|c|c|}
\hline Variables & $\begin{array}{c}\text { Total } \\
\mathrm{N}=\mathbf{3 0 5}\left(\%^{\dagger}\right)\end{array}$ & $\begin{array}{c}\text { Men } \\
\mathbf{n}=128\left(\%^{\dagger}\right)\end{array}$ & $\begin{array}{c}\text { Women } \\
\mathbf{n}=\mathbf{1 7 7}\left(\%^{\dagger}\right) \\
\end{array}$ & $t$ or $x^{2}$ ( $p$ value) \\
\hline Mobility & & & & $12.61(0.001)$ \\
\hline No Problems & $205(72.2)$ & $96(82.0)$ & $109(63.8)$ & \\
\hline Problems & $100(27.8)$ & $32(18.0)$ & $68(36.2)$ & \\
\hline Self-Care & & & & $1.24(0.303)$ \\
\hline No Problems & $268(90.8)$ & $114(92.8)$ & $154(89.1)$ & \\
\hline Problems & $37(9.2)$ & $14(7.2)$ & $23(10.9)$ & \\
\hline Usual Activity & & & & $6.06(0.036)$ \\
\hline No Problems & $235(79.7)$ & $105(85.8)$ & $130(74.4)$ & \\
\hline Problems & $20.3(70)$ & $23(14.2)$ & $47(25.6)$ & \\
\hline Pain/Discomfort & & & & $11.30(0.001)$ \\
\hline No Problems & $190(67.1)$ & $93(76.8)$ & $97(58.7)$ & \\
\hline Problems & $32.9(115)$ & $35(23.2)$ & $80(41.3)$ & \\
\hline Anxiety/Depression & & & & $0.31(0.638)$ \\
\hline No Problems & $254(80.7)$ & $111(82.0)$ & $143(79.5)$ & \\
\hline Problems & $19.3(51)$ & $17(18.0)$ & $34(20.5)$ & \\
\hline Overall QOL, VAS, mean $\dagger$ (SE $\dagger$ ) & $70.45(2.6)$ & $71.6(1.82)$ & $69.5(1.72)$ & $0.81(0.419)$ \\
\hline EQ-5D index & $0.88(0.02)$ & $0.91(0.01)$ & $0.85(0.02)$ & $3.07(0.003)$ \\
\hline
\end{tabular}

${ }^{\dagger}$ weighted values. 
in disease management, health behaviors, and QOL in Koreans with asthma. The mean age at diagnosis among men was significantly lower than that of women in this study. This result is consistent with previous studies $[14,15]$, which reported that the incidence of asthma among women 35 years or older was increasing, and that the number of women with asthma was higher than that of men in individuals over 40 years of age [14]. The age at diagnosis of asthma seems to differ by gender.

Both men and women had poor health behaviors in this study, and there were gender differences in asthma symptoms. Manfreda and his colleges [16] reported that women experienced more symptoms, such as dyspnea and wheezing, than men; therefore, women received more medical treatments. In this study, more women also reported wheezing at rest than men. However, although $51 \%$ women reported wheezing at rest, only $25 \%$ of this sample received asthma treatments. Adherence to asthma medication schedules was moderate for both men and women and there were no significant gender differences. Therefore, effective interventions to improve self-management of their disease should be developed for Koreans with asthma.

In psychological health status, the rate of women with depression was significantly higher than that of men. This result is consistent with the results of a previous study that found women with mild asthma had more episodes of anxiety and depression than men [17]. In addition, Koreans women with asthma might be likely to be more depressed than overall Korean populations even though we did not compare depression between Korean women with asthma and without asthma in this study. However, Sung [18] reported that $13 \%$ of participants were depressed in last two weeks and $3 \%$ of them were diagnosed depression generally using national data, while about $27 \%$ of women with asthma reported depression in this sample. Interventions focusing on psychological issues may need to be tailored more toward women.

The overall QOL of this sample was moderate and a gender difference was not observed. However, the EQ$5 \mathrm{D}$ index score of women was significantly lower than the score of men. The EQ-5D index scores of the participants was lower than the scores of overall Koreans aged 19 years or over and Koreans with osteoarthritis and hypertension [19], and was similar to the scores of Koreans with cancer and chronic obstructive pulmonary disease [6]. The results of prior QOL studies are similar to the results of this study; in those studies, the overall QOL of patients with asthma was low, and women had a lower QOL than men [10,20,21].

In the subscales of the EQ-5D, the number of women reporting problems with mobility, usual activities, and pain/discomfort was significantly higher than the number of men. More women than men also reported problems on the subscales of self-care and anxiety/depression, even though there were no significant gender differences. Sinclaire and Tolsma [21] found that women with asthma were more likely to complain of discomfort, symptoms of wheezing, and shortness of breath, which supports the results of this study. Therefore, women with asthma might need different symptom management and health behavior strategies than men. Health care providers should evaluate and address health status by gender for individuals with asthma.

The study has some limitations. First, there is sampling bias due to the use of the self-report instruments in the KNHANES IV. Some of the information was subjective and might differ from a professional evaluation. Second, the KNHANES IV used the EQ-5D to evaluate QOL, which is useful when comparing QOL among people with varying diseases and countries, but this instrument lacks sensitivity in the assessment of specific issues affecting people with asthma. Third, we did not compare health status and health behaviors between Koreans with asthma and without asthma. Because the differences s of sample sizes between them was big, there was the lack of statistical stability. Further study needs to examine the difference between people with asthma and without asthma.

\section{CONCLUSION}

Although there are some limitations, this study found gender differences in disease management, health status, and QOL of Koreans with asthma. Women with asthma were more likely to have psychological problems and discomfort related to asthma symptoms than men. The findings of this study are important for the development of effective and gender-sensitive interventions aimed at enhancing health status and QOL among patients with asthma.

\section{REFERENCES}

[1] World Health Organization (2011) Asthma. 2011 http://www.who.int/respiratory/asthma/en/

[2] Center for Disease Control and Prevention (2011). Asthma fast facts.

http://www.cdc.gov/asthma/pdfs/asthma fast facts statis tics.pdf

[3] Korea Ministry for Health Welfare and Family Affairs (2011) Status of Chronic Disease in Korea. 2011 http://www.index.go.kr/egams/stts/jsp/potal/stts/PO_STT $\underline{\text { S IdxMain.jsp?idx cd }=1438 \& b b s=\text { INDX } 001}$

[4] Strine, T.W., et al. (2008) Impact of depression and anxiety on quality of life, health behaviors, and asthma control among adults in the United States with asthma, 2006. Journal of Asthma, 45, 123-133. http://dx.doi.org/10.1080/02770900701840238 
[5] Ford, E.S., et al. (2004) Determinants of quality of life among people with asthma: Findings from the behavioral risk factor surveillance system. Journal of Asthma, 41, 327-336. http://dx.doi.org/10.1081/JAS-120026090

[6] Jung, Y. and Lee, H. (2011) Chronic obstructive pulmonary disease in Korea: Prevalence, risk factors, and quality of life. Journal of Korean Academy of Nursing, 41, 149-156. http://dx.doi.org/10.4040/jkan.2011.41.2.149

[7] Oh, E.G., et al. (2010) Health behaviour and quality of life in Korean adults with respiratory disease: National health survey, 2005. International Journal of Tuberculosis \& Lung Disease, 14, 772-778.

[8] Baibergenova, A., et al. (2006) Sex differences in hospital admissions from emergency departments in asthmatic adults: A population-based study. Ann Allergy Asthma Immunology, 96, 666-672. http://dx.doi.org/10.1016/S1081-1206(10)61063-0

[9] Kynyk, J.A., Mastronarde, J.G. and McCallister, J.W. (2011) Asthma, the sex difference. Current Opinion in Pulmonary Medicine, 17, 6-11. http://dx.doi.org/10.1097/MCP.0b013e3283410038

[10] Chhabra, S. and Chhabra, P. (2011) Gender differences in perception of dyspnea, assessment of control, and quality of life in asthma. Journal of Asthma, 48, 609-615. http://dx.doi.org/10.3109/02770903.2011.587577

[11] Katsura, H., et al. (2007) Gender-associated differences in dyspnoea and health-related quality of life in patients with chronic obstructive pulmonary disease. Respirology, 12, 427-432. http://dx.doi.org/10.1111/j.1440-1843.2007.01075.x

[12] Korea Center for Disease Control and Prevention (2010) Korea Health Statistics 2009: Korea National Health and Nutrition Examination Survey (KNHANES IV-3). http://knhanes.cdc.go.kr/

[13] Dolan, P. (1997) Modeling valuations for EuroQol health states. Medical Care, 35, 1095-1108. http://dx.doi.org/10.1097/00005650-199711000-00002

[14] Leynaert, B., et al. (2012) Gender differences in prevalence, diagnosis and incidence of allergic and non-allergic asthma: A population-based cohort. Thorax, 67, 625631. http://dx.doi.org/10.1136/thoraxjnl-2011-201249

[15] Raherison, C., et al. (2009) Evolution of asthma severity in a cohort of young adults: Is there any gender difference? PLoS One, 4, e7146. http://dx.doi.org/10.1371/journal.pone.0007146

[16] Manfreda, J., et al. (2004) Geographic and gender variability in the prevalence of bronchial responsiveness in Canada. Chest, 125, 1657-1664. http://dx.doi.org/10.1378/chest.125.5.1657

[17] Tovt-Korshynska, M., et al. (2001) Gender differences in psychological distress in adults with asthma. Journal of Psychosomatic Research, 51, 629-637. http://dx.doi.org/10.1016/S0022-3999(01)00254-9

[18] Sung, G. (2007) Study on relationships between depresssion and the quality of life (EQ-5D): Centered on the subjects of "Survey on national health and nutrition the forth period the first year". Master Thesis, Yonsei University, Seoul.

[19] Chung, Y.H. (2011) A report on the health related quality of life in Korean. Health welfare Policy Forum, 182, 614.

[20] Belloch, A., et al. (2003) Gender differences in healthrelated quality of life among patients with asthma. Journal of Asthma, 40, 945-953. http://dx.doi.org/10.1081/JAS-120024595

[21] Sinclair, A. and Tolsma, D. (2006) Gender differences in asthma experience and disease care in a managed care organization. Journal of Asthma, 43, 363-367. http://dx.doi.org/10.1080/02770900600705334 